\title{
Long-term outcomes and prognostic factors of patients with pulmonary carcinoid tumors
}

\author{
A. STOLZ ${ }^{1, *}$, T. HARUSTIAK ${ }^{1}$, J. SIMONEK ${ }^{1}$, J. SCHUTZNER ${ }^{1}$, O. POLANECKY ${ }^{1}$, J. BURKERT ${ }^{2}$, R. LISCHKE ${ }^{1}$ \\ ${ }^{1} 3 r d$ Department of Surgery, First Faculty of Medicine, Charles University, University Hospital Motol, Prague, Czech Republic; ${ }^{2}$ Department of \\ Cardiac Surgery, University Hospital Motol, Prague, Czech Republic \\ *Correspondence: alan.stolz@fnmotol.cz
}

Received September 5, 2014 / Accepted December 1, 2014

\begin{abstract}
The aim of the study was to evaluate type of surgery, long-term survival and factors influencing outcome of pulmonary carcinoid tumors. We reviewed our database of 137 patients surgically treated for typical or atypical carcinoid tumors at our department between 1998 and 2013. There were 95 (69\%) patients with typical carcinoid (87 N0, 6 N1, 2 N2) and 42 (31\%) with atypical carcinoid ( 26 N0, 8 N1, 8 N2). Patients with atypical carcinoid were older than those with typical carcinoid (median age of $57 \pm 8.1$ and $50.5 \pm 15.8$ years, respectively, $\mathrm{p}<0.00001$ ). The resection performed consisted of $6(4.4 \%)$ pneumonectomies, $110(80.1 \%)$ lobectomies and bilobectomies, 15 (11\%) sleeve lobectomies, $2(1.5 \%)$ resections of main bronchus and 4 (3\%) wedge resections. Overall 5- and 10-year survival rates for different tumors were as follows: typical carcinoid: $97.2 \%$ and $89.9 \%$, respectively; atypical carcinoid $71.1 \%$ and $62.2 \%$, respectively. Statistical analyses indicated that histology (typical carcinoid, $\mathrm{p}<0.00001$ ), age (less than 45 years, $\mathrm{p}=0.004$ ) and nodal status ( $\mathrm{N} 0, \mathrm{p}=0.0002$ ) were significant prognostic factors for better prognosis. Histological sub-type and nodal involvement appear as the most important factors influencing the prognosis. Systemic lymphadenectomy is recommended and should always be performed.
\end{abstract}

Key words: pulmonary carcinoid, lung resection, survival

Pulmonary carcinoid tumors constitute $0.5-3 \%$ of all resected lung tumors and about $25 \%$ of all carcinoids $[1,2]$. They arise from Kultcitsky's cells, a specialized network of neuroendocrine cells which synthesize bioactive amines, such as serotonin, and peptide hormones. Depending on the degree of mitotic activity and necrosis, tumors are further sub classified into typical and atypical carcinoids. In typical carcinoid (TC), there are $<2$ mitoses per $2 \mathrm{~mm}^{2}$ ( $10 \mathrm{x}$ high-power field) and no necrosis. In atypical carcinoid (AC), there is a demonstration of necrosis and/or presence of 2-10 mitoses per 2 $\mathrm{mm}^{2}$ (10 x high-power field) [3].

Carcinoid tumors can be "non-functioning" tumors, presenting as a tumor mass, or "functioning" tumors secondary to the production of several biopeptides leading to the carcinoid syndrome. Appropriate diagnostic and therapeutic measures are very important. Proper patient management can lead to cure, particularly if the tumor is fully resected with significant prolongation of survival. For better understanding of pulmonary carcinoid tumors, we reviewed our institutional experience with these tumors. We aimed to determine the clinical, pathological, and bronchoscopical characteristics, long-term outcomes and prognostic factors of patients, who underwent surgical resection of pulmonary carcinoid tumors between the years 1998 and 2013.

\section{Patients and methods}

We retrospectively reviewed our prospective database of 137 patients surgically treated for carcinoid tumors at the $3^{\text {rd }}$. Department of Surgery, University Hospital, Prague from 1998 to 2013. The age, gender, smoking status (non smokers: patients who had never smoked on regular basis; ex-smokers: regular smokers who had stopped smoking with the initiating of their investigations into diagnosing their lung cancer by a period in excess of 60 days before surgery; and current smokers: patients who were smoking regularly till surgery), presenting symptoms, localization, size (maximum diameter in millimeters), presence of endocrine syndromes (Cushing's and carcinoid syndrome), surgical procedure, postoperative staging, histological type, and survival rates were recorded. 
Preoperative evaluation included radiological investigations (chest X-ray, chest computer tomography, abdominal ultrasound), and bronchoscopy. According to bronchoscopy, the tumors we classified as central if presented directly at bronchoscopy or peripheral, when the tumor was not visible at endoscopy. Some patients underwent analysis of the expression of somatostatin receptors in the primary tumor and/or in secondary localizations by using Octreotid marked Indium
111 (Octreotide-scan). The tumors were classified according to the 1999 WHO criteria including Travis's criteria for atypical carcinoid tumors and their distinction from typical carcinoid tumors [3]. The epidermal growth factor receptor (EGFR) was not routinely examined so we did not use it in our statistical analysis.

The statistical analysis was performed with the SPSS programme (Statistical Package for Social Sciences), version

Table 1. Clinical characteristics

\begin{tabular}{|c|c|c|c|c|}
\hline & Total, n (\%) & TC, n (\%) & $\mathrm{AC}, \mathrm{n}(\%)$ & $p$-value \\
\hline Patients & $137(100 \%)$ & $95(69.3 \%)$ & $42(30.7 \%)$ & \\
\hline \multicolumn{5}{|l|}{ Sex } \\
\hline Male & $69(50.3 \%)$ & $48(50.5 \%)$ & $21(50 \%)$ & 0.95 \\
\hline Female & $68(49.7 \%)$ & $47(49.5 \%)$ & $21(50 \%)$ & \\
\hline Age (median y, \pm SD) & $54.5 \pm 14.5$ & $50.5 \pm 15.8$ & $57 \pm 8.1$ & $<0.0001$ \\
\hline BMI (median) & 27 & 27 & 28 & 0.67 \\
\hline FEV1 $1 \%)$ & 78.4 & 79.7 & 77.5 & 0.54 \\
\hline \multicolumn{5}{|l|}{ Location } \\
\hline Central & $88(64.2 \%)$ & $66(69.5 \%)$ & $22(52.4 \%)$ & $<0.05$ \\
\hline Peripheral & $49(35.8 \%)$ & $29(30.5 \%)$ & $20(47.6 \%)$ & \\
\hline Tumor size (median,mm $\pm \mathrm{SD})$ & $23 \pm 12.9$ & $20 \pm 10.7$ & $28 \pm 15.8$ & 0.005 \\
\hline \multicolumn{5}{|l|}{ Symptoms } \\
\hline Asymptomatic & $49(35.8 \%)$ & $29(30.5 \%)$ & $20(47.6 \%)$ & 0.25 \\
\hline Fever & $57(41.6 \%)$ & $43(45.2 \%)$ & $14(33.3 \%)$ & \\
\hline Cough & $43(31.4 \%)$ & $29(30.5 \%)$ & $14(33.3 \%)$ & \\
\hline Hemoptysis & $13(9.5 \%)$ & $11(8 \%)$ & $2(4.8 \%)$ & \\
\hline Carcinoid syndrome & $1(0.7 \%)$ & $0(0 \%)$ & $1(2.3 \%)$ & \\
\hline Cushing's syndrome & $5(3.6 \%)$ & $3(3.2 \%)$ & $2(4.7 \%)$ & \\
\hline Preoperative verification & $78(56.9 \%)$ & $58(61 \%)$ & $20(47.6 \%)$ & 0.14 \\
\hline \multicolumn{5}{|l|}{ Type of surgery } \\
\hline Lobectomy & $90(65.5 \%)$ & $65(68.4 \%)$ & $25(59.5 \%)$ & 0.30 \\
\hline Bilobectomy & $20(14.6 \%)$ & $11(11.6 \%)$ & $9(21.4 \%)$ & \\
\hline Sleeve lobectomy & $15(11 \%)$ & $12(12.6 \%)$ & $3(7.2 \%)$ & \\
\hline Pneumonectomy & $6(4.4 \%)$ & $1(1.1 \%)$ & $5(11.9 \%)$ & \\
\hline Wedge resection & $4(3 \%)$ & $4(4.2 \%)$ & $0(0 \%)$ & \\
\hline Bronchial resection & $2(1.5 \%)$ & $2(2.1 \%)$ & $0(0 \%)$ & \\
\hline \multicolumn{5}{|l|}{ Stages } \\
\hline I & $115(83.9 \%)$ & $86(90.5 \%)$ & $29(69 \%)$ & 0.0048 \\
\hline II & $14(10.3 \%)$ & $7(7.4 \%)$ & $7(16.7 \%)$ & \\
\hline III & $7(5.1 \%)$ & $2(2.1 \%)$ & $5(11.9 \%)$ & \\
\hline IV & $1(0.7 \%)$ & $0(0 \%)$ & $1(2.4 \%)$ & \\
\hline \multicolumn{5}{|l|}{ Lymph nodes- N status } \\
\hline No & $116(84.7 \%)$ & $87(91.6 \%)$ & $29(69 \%)$ & $<0.0001$ \\
\hline N1 & $13(9.5 \%)$ & $6(6.3 \%)$ & $7(16.7 \%)$ & \\
\hline $\mathrm{N} 2$ & $8(5.8 \%)$ & $2(2.1 \%)$ & $6(14.3 \%)$ & \\
\hline \multicolumn{5}{|l|}{ Survival } \\
\hline 5-year survival & $89.3 \%$ & $97.2 \%$ & $71.1 \%$ & $<0.0001$ \\
\hline 10-year survival & $81.6 \%$ & $89.9 \%$ & $62.2 \%$ & $<0.0001$ \\
\hline
\end{tabular}


12.0. Survival was estimated according to the Kaplan-Meier method. The statistical difference between the survival curves was determined using the log-rank test. Association between categorical variables were determined by using the chi-square test. Multivariate analysis by Cox proportional hazard model was used to investigate the relative importance of different prognostic factors. The parameters evaluated were age, sex, localization (central or peripheral), type of surgery, nodal status and histology. A $p$-value lower than 0.05 was considered significant. A $p$-value lower than 0.01 was considered highly significant.

\section{Results}

The demographic, pathological and surgical data of our patients are summarized in Table 1 . The 137 patients consisted of 69 male (50.5\%) and 68 female (49.5\%). Their ages ranged between 15 and 81 years (median age $50.3 \pm 14.5$ years). There were statistically significant differences between the TC and $\mathrm{AC}$ groups in terms of median age, with patients in the AC group tending to be older ( 50.5 vs. 57 years, $\mathrm{p}<0.0001$ ). Bronchial carcinoid tumors occur in patients that are on average a decade younger than patients with non-small cell lung cancer. There were no significant differences in gender, BMI, performance or spirometric values between histological subtypes groups.

On the basis of bronchoscopic findings 88 carcinoids (64.2\%) were centrally located. The percentage of central tumors were higher in TC than in AC $(69.5 \%$ vs. $52.4 \%$, $\mathrm{p}<0.05)$ Endoscopic biopsy was performed in 79 patients. In central carcinoids bronchoscopic biopsy permitted a correct preoperative carcinoid tumor diagnosis in 71 (89.9 \%) patients. Eight specimens $(9.1 \%)$ were diagnosed as non-small cell lung cancer. In 4 patients (3\%), a laser-assisted resection of the endoluminal component of the tumor was used to relieve the obstructive symptoms and to better locate the base of carcinoid.

Out of the 137 carcinoid tumor cases, 78 patients (57\%) were non-smokers, 59 patients $(43 \%)$ were current or exsmokers. In the current or ex-smoker group, 35 of the patients were TC ( $37 \%$ of all TCs), and 24 of them were AC (57\% of the all ACs). Comparison of smoking habits between the TC group and the AC group showed significant differences, with more smoking history in the AC group ( $\mathrm{p}=0.04)$.

Table 2. Multivariate Cox regression analyses of prognostic factors

\begin{tabular}{lcc}
\hline & HR $(95 \% \mathrm{CI})$ & $p$ \\
\hline Sex (male) & $2.17(0.832-5.656)$ & 0.11 \\
Age & $1.09(1.035-1.163)$ & 0.001 \\
Histology (AC) & $5.29(1.714-16.150)$ & 0.003 \\
Lymph node positivity (N1,2) & $2.5(0.897-6.500)$ & 0.048 \\
Tumor location (central) & $1.51(0.598-3.815)$ & 0.38 \\
\hline
\end{tabular}

(AC-atypical carcinoid, N1,2-nodal involvement)
Symptoms were present in 88 patients (64.2\%). The most frequent presenting symptoms were recurrent respiratory infection in 57 patients (41.6\%), persistent cough in 43 (31.4\%), hemoptysis in 13 (9.5\%) patients. Carcinoid syndrome was observed in $1(0.7 \%)$ and Cushing's syndrome in $5(3.7 \%)$ patients. Forty-nine patients (35.8\%) were asymptomatic at the time of presentation.

The lesions ranged in size from 5 to $80 \mathrm{~mm}$. Median lesion size was $23 \pm 12.9 \mathrm{~mm}$. Atypical carcinoids were larger than TCs ( 28 vs. $20 \mathrm{~mm}, \mathrm{p}=0.005$ ).

Carcinoid tumors were located in the right lung in 84 (61.3\%) patients. The most common site was the left upper lobe (27.6\%). Most of the tumors arose in the major bronchi (66.2\%). Six (6.8\%) tumors were located in the mainstem bronchi and eighty two $(93.2 \%)$ in the lobar bronchi.

According to the histological findings there were 95 (69.3\%) patients with TC and $42(30.7 \%)$ with AC. In Table 1 we show the differences in pathological characteristics between these two histological subtypes. Fourteen (10.2\%) had involvement of the hilar lymph nodes (N1) and $10(7.3 \%)$ had positive mediastinal N2 lymph nodes. Patients with TC had a lower rate of nodal involvement compared with patients with AC $(8.4 \%$ vs. $38 \%, \mathrm{p}<0.0001)$.

Overall 5- and 10-year survival rates were $89.3 \%$ and $81.6 \%$ (Table 1). Overall survivals were of significant difference between two types of histology $(\mathrm{p}<0.0001)$. For TC and AC, 5 - and 10 -year survival rates were $97.2 \%$ and $89.9 \%, 71.1 \%$ and $62.2 \%$ respectively (Figure 2). Overall survival rates differed significantly between $\mathrm{N} 0$ and $\mathrm{N} 1,2$ groups $(\mathrm{p}<0.0001)$. Patients with no nodal involvement (N0) had 5- and 10-year survival rates of $95.1 \%$ and $91 \%$. Survival rates of patients with nodal involvement $(\mathrm{N} 1,2)$ were $72.6 \%$ and $59 \%$ (Figure 2).

Univariate analysis regarding the effects of demographics, stage, and treatment on overall survival was conducted using Cox proportional hazards regression. Multivariate models then were created using covariates significant under univariate analysis at the $\mathrm{p}<0.05$ level. Multivariate Cox regression analyses of overall survival of all 137 patients indicated that atypical carcinoid $(p=0.003)$, age $(p=0.001)$ and nodal status positivity $(\mathrm{p}=0.048)$ were significant prognostic factors for worse prognosis in multivariate analyses (Table 2).

\section{Discussion}

Surgery represents the cornerstone of treatment for pulmonary carcinoids and is the treatment of choice, achieving a long-term survival in the case of radical operation. In the present study, carcinoid tumors were found in $1 \%$ of malignant pulmonary tumors. The majority were typical carcinoids tumors (69.3\%). Their histological nature, characterized by cellular organization in nests, and the rich fibrovascular stroma allow recognition of their neuroendocrine phenotype through routine microscopic techniques. The possibility of demonstrating the cells' neurosecretory capacity contributes to a strengthening of neuroendocrine differentiation in 


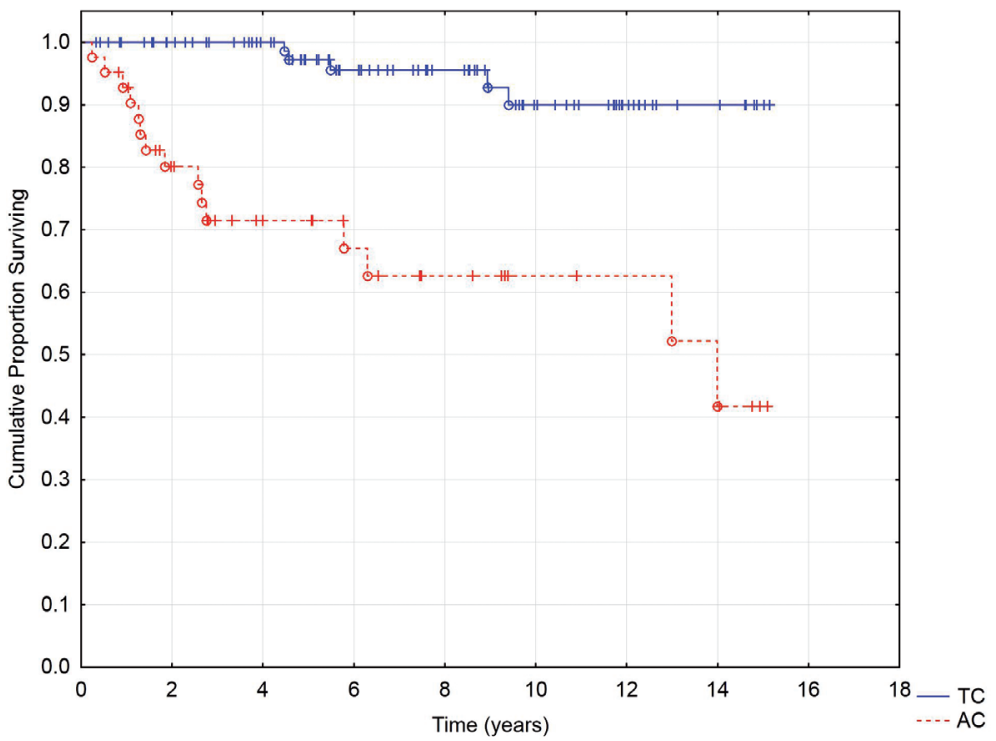

Figure 1. Overall survival by histology.

Figure legends: TC-typical carcinoid, AC-atypical carcinoid.

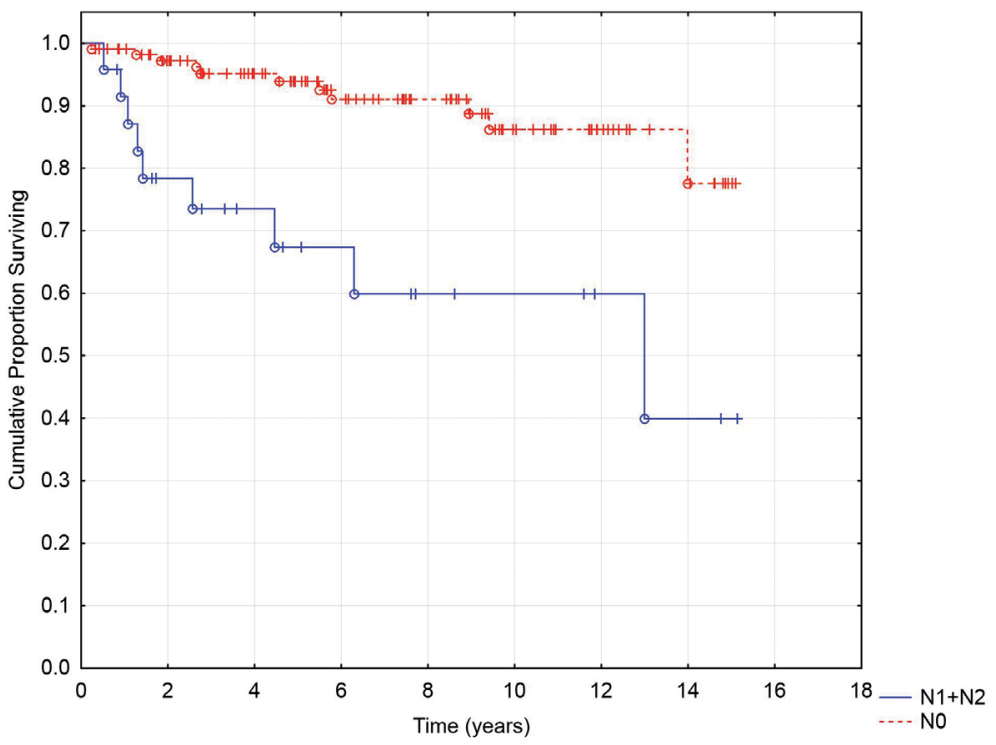

Figure 2. Overall survival by nodal status.

Figure legends: N0- no nodal involvement, N1+2- nodal involvement.

these tumors. On the basis of these facts, typical and atypical carcinoids are included in the spectrum of neuroendocrine neoplasm of the lung.

In our study we confirmed the relationship between the increase in mean age and histological degradation $[2,4,5]$. The difference in mean age between our patients with typical and atypical carcinoid tumors was 9 years. Our study did not confirm other studies that the incidence of these tumors differs between the sexes and we did not find the link between an increased incidence in males and a higher degree of malignancy $[2,5]$.

We found a significant difference between the AC and TC group with respect to smoking history with a higher number of patients with a smoking history in AC group ( $\mathrm{p}=0.04)$. There are studies showing no relation between the incidence of tobacco and histological aggressiveness of the disease $[4,6]$ as well as reports showing the possible relationship between $\mathrm{AC}$ and smoking history $[7,8]$. 
In the most of the published series, the majority of the patients with carcinoid tumors have symptoms (55-85\%) $[4,7,8]$. Two-thirds of our patients had symptoms. The recurrent respiratory infection was the most common one. This correlates with the finding that two-thirds of carcinoid tumors are localized centrally causing bronchial obstruction. Our study confirmed, similar to other reports, that TC develop a central location more frequently than AC [7,9]. A significant difference in size was found in our study between TC and AC. The correlation of this finding with the results of other reports reaffirms the existing relationship between increased tumor size and advanced histological deterioration $[2,4]$.

Surgery represents the cornerstone of treatment for pulmonary carcinoids and it is the treatment of choice, achieving a long-term survival in case of radical operation [5]. Despite this, there are some trends to be discussed. Last period can be characterized by a significant increase in the number of sleeve resections or bronchoplastic procedures in centrally localized tumors, with significant decrease of pneumonectomies. This is due to good surgical results of such parenchyma-sparing procedures which do not alter the oncological result and guarantee a better quality of life. At our department we prefer sleeve resection to wedge bronchoplasty. From the oncological point of view they are comparable, with reference to free margin of resection. Wedge resection may be more likely to lead to kinking of the bronchial tree, which may be the reason for complications such as atelectasis, stenosis or dehiscence [10].

There is a lack of comprehensive randomized studies to compare a lobectomy or greater resection and sublobar resection [11]. There is a tendency for sublobar resections to be performed in either early stage typical carcinoid patients or patients with preoperative pulmonary function tests that preclude conventional anatomical resection. Afoke suggests that sublobar resection with lymph node dissection for accurate staging might be sufficient for patients with typical carcinoids [11]. Similar results were published by Fox [12]. In their study they performed retrospective review of 3270 patients diagnosed with typical or atypical carcinoid. The mean overall survival was slightly better in lobectomy group compared with those undergoing sublobar resection ( $86 \mathrm{vs.} 83 \mathrm{mo}$; $\mathrm{p}=0.008)$. By using multivariate analysis, sublobar resection was not inferior to lobectomy with regard to disease-specific interval $(p<0.05)$. Very often wedge-sublobar resections are performed in patients with a peripherally-located lesion. The surgical management then depends on the results of the frozen section. The differentiation between atypical carcinoid and large cell neuroendocrine carcinoma during frozen section may be challenging for neuroendocrine tumors of the lung. Thus, the intraoperative decision-making process for the appropriate oncological treatment can be difficult

Carcinoid tumors belong to the non-small cell lung cancer classification group, so there is a risk of lymphatic spread. Cardillo reported study of 163 patients with carcinoid tumor. In the TC group the percentage of lymphatic spread was $11.6 \%$
(N1) [13]. In the AC group there were $43 \%$ positive $\mathrm{N} 1$ nodes and 21\% positive N2 nodes. Mineo 2005 emphasized the relevance of micrometastasis detection by immunohistochemical techniques: from 17 to $28 \%$ increase in TC group and from 50 to $88 \%$ increase in AC group [14]. Literature shows a similar percentage of $\mathrm{N} 2$ patients in TC group (0-5\%) like in our study $(2.1 \%)[2,5,8,9,15]$. In AC group, the higher percentage of N2 patients (11-25\%) was confirmed by our study (19\%). Due to these results, in both groups, we recommend to perform a systemic nodal dissection as a routine procedure with pulmonary resection.

Overall survival for TC in our study at 5 - and 10- years was $97.2 \%$ and $89.9 \%$, respectively. Similar results were reported by other authors (89\%-97\% and 73.3\%-92\%, respectively) $[7,8,9]$. Overall survival for AC in the present study at 5 - and 10 - years was $71.1 \%$ and $62.2 \%$, respectively. These results are comparable with results from other studies $(70 \%-79 \%$ and $56 \%-67 \%$, respectively) $[2,8,9]$. Pulmonary carcinoid tumors have better biological behavior and prognosis, compared with other lung cancers. However, atypical carcinoids tend to be more aggressive, associated with higher rate of nodal involvement and a worse survival rate.

Surgical resection remains the mainstay of treatment for pulmonary carcinoids. Initial bronchoscopic treatment can be applied to improve presurgical condition, to obtain tissue samples for proper histological classification, and to ensure less extensive parenchymal resection. There are some reports of bronchoscopic treatment using ablation techniques. Bertoletti reported their experience on a series of 18 patients with intraluminal typical carcinoids, treated bronchoscopically by cryotherapy with single local recurrence [16]. In the recent study by Brokx, initial bronchoscopic treatment with Nd:YAG laser or electrocautery and mechanical removal was applied in 72 patients with intraluminal bronchial carcinoids [17]. Successful tumor eradication was achieved in 33 of $72(45 \%)$ cases. Patient selection for endobronchial removal is important, because only about 5-10\% are polyp like endobronchial structures without extension through the cartilaginous wall $[1,17]$. Bertoletti reported that among 10 patients showing strictly endoluminal TC who were potentially eligible for bronchoscopic treatment, surgery discovered $\mathrm{N} 1$ and $\mathrm{N} 2$ lymphatic spread in 2 of them (20\%) [16]. In our opinion bronchoscopic treatment of carcinoid should be restricted to elderly patients or patients with a high operative risk.

Approximately $20 \%$ of all carcinoid tumors present as purely intraluminal polyp-like endobronchial lesions without gross radiological detectable involvement of the bronchial wall and lung parenchyma [1]. One choice of radical treatment are endoscopic resection techniques, as mentioned above. Another possibility is resection of the central airway without removal of any parenchyma for endobronchial carcinoid tumors. Nowak published a retrospective study of 13 patients with pure bronchoplastic resection [18]. There were five resections of the main stem bronchus, four resections of the intermediate bronchus and three sleeve resections of the 
middle lobe bronchus. Twelve tumors were typical carcinoids, and there was one atypical carcinoid. In this case, a tumorlet was identified at 5 years in contralateral airway and viewed as a metachronous new lesion. In our series, we performed two resections of the left main stem bronchus with no postoperative complications and recurrence. We think, that resection of the main stem bronchus should be the treatment of choice, especially in the case of typical carcinoids. In the presence of atypical carcinoid the situation may by different, because of a higher metastatic and malignant potential. Further randomized studies are needed to assess the postoperative morbidity, long-term survival and disease recurrence between these two approaches.

Acknowledgements: Supported by the project by Ministry of Health, Czech Republic - conceptual development of research organization, University Hospital Motol, Prague,Czech Republic, 00064203.

\section{References}

[1] DETTERBECK FC. Management of carcinoid tumors. Ann Thorac Surg. 2010; 89: 998-1005. http://dx.doi.org/10.1016/j. athoracsur.2009.07.097

[2] GARCIA-YUSTE M, MATILLA JM, CUETO A, PANIAGUA JM, RAMOS G, et al. Typical and atypical carcinoid tumours: analysis of the experience of the Spanish Multi-centric Study of Neuroendocrine Tumours of the Lung. Spanish Multicentric Study of Neuroendocrine Tumours of the Lung for the Spanish Society of Pneumonology and Thoracic Surgery (EMETNE-SEPAR). Eur J Cardiothorac Surg. 2007; 31: 192-7. http://dx.doi.org/10.1016/j.ejcts.2006.11.031

[3] TRAVIS WD, RUSH W, FLIEDER DB, FALK R, FLEMING $\mathrm{MV}$, et al. Survival analysis of 200 pulmonary neuroendocrine tumors with clarification of criteria for atypicalcarcinoid and its separation from typical carcinoid. Am J Surg Pathol. 1998; 22: 934-44. http://dx.doi.org/10.1097/00000478-199808000$\underline{00003}$

[4] FERGUSON MK, LANDRENEAU RJ, HAZELRIGG SR, ALTORKI NK, NAUNHEIM KS, et al. Long-term outcome after resection for bronchial carcinoid tumors. Eur J Cardiothorac Surg. 2000; 18: 156-61. http://dx.doi.org/10.1016/ S1010-7940(00)00493-0

[5] REA F, RIZZARDI G, ZUIN A, MARULLI G, NICOTRA S, et al. Outcome and surgical strategy in bronchial carcinoid tumors: single institution experience with 252 patients. Eur J Cardiothorac Surg. 2007; 31: 186-91. http://dx.doi. org/10.1016/j.ejcts.2006.10.040

[6] BINI A, BRANDOLINI J, CASSANELLI N, DAVOLI F, DOLCI G, et al. Typical and atypical pulmonary carcinoids: our institutional experience. Interact Cardiovasc Thorac Surg. 2008; 7: 415-8. http://dx.doi.org/10.1510/ icvts.2007.173328
[7] AYDIN E, YAZICI U, GULGOSTEREN M, AGACKIRAN Y, KAYA S, et al. Long-term outcomes and prognostic factors of patients with surgically treated pulmonary carcinoid: our institutional experience with 104 patients. Eur J Cardiothorac Surg. 2011; 39: 549-54. http://dx.doi.org/10.1016/j. ejcts.2010.08.010

[8] FINK G, KRELBAUM T, YELLIN A, BENDAYAN D, SAUTE $\mathrm{M}$, et al. Pulmonary carcinoid: presentation, diagnosis, and outcome in 142 cases in Israel and review of 640 cases from the literature. Chest. 2001; 119: 1647-51. http://dx.doi. org/10.1378/chest.119.6.1647

[9] ZHONG CX, YAO F, ZHAO H, SHI JX, FAN LM. Long-term outcomes of surgical treatment for pulmonary carcinoid tumors: 20 years' experience with 131 patients. Chin Med J (Engl). 2012; 125: 3022-6.

[10] JANIK M, LUCENIC M, BENEJ R, HARUSTIAK S. Surgical treatment of lung carcinoids. Onkologia. 2011; 6: 336-338.

[11] AFOKE J, TAN C, HUNT I, ZAKKAR M. Is sublobar resection equivalent to lobectomy for surgical management of peripheral carcinoid? Interact Cardiovasc Thorac Surg. 2013; 16: 858-63. http://dx.doi.org/10.1093/icvts/ivt067

[12] FOX M, VAN BERKEL V, BOUSAMRA M, SLOAN S, MARTIN RC. Surgical management of pulmonary carcinoid tumors: sublobar resection versus lobectomy. Am J Surg. 2013; 205: 200-8. http://dx.doi.org/10.1016/j.amjsurg.2012.05.008

[13] CARDILLO G, SERA F, DI MARTINO M, GRAZIANO P, GIUNTI R, et al. Bronchial carcinoid tumors: nodal status and long-term survival after resection. Ann Thorac Surg. 2004; 77: 1781-5. http://dx.doi.org/10.1016/j.athoracsur.2003.10.089

[14] MiNEO TC, GUGGINO G, MiNEO D, VANNI G, AMBROGI V. Relevance of lymph node micrometastases in radically resected endobronchial carcinoid tumors. Ann Thorac Surg. 2005; 80: 428-32. http://dx.doi.org/10.1016/j. athoracsur.2005.02.083

[15] WURTZ A, BENHAMED L, CONTI M, BOUCHINDHOMME B, PORTE H. Results of systematic nodal dissection in typical and atypical carcinoid tumors of the lung. J Thorac Oncol. 2009; 4: 388-94 http://dx.doi.org/10.1097/ ITO.0b013e3181951aa6

[16] BERTOLETTI L, ELLEUCH R, KACZMAREK D, JEANFRANCOIS R, VERGNON JM. Bronchoscopic cryotherapy treatment of isolated endoluminal typical carcinoid tumor. Chest. 2006; 130: 1405-11. http://dx.doi.org/10.1378/ chest.130.5.1405

[17] BROKX HA, RISSE EK, PAUL MA, GRUNBERG K, GOLDING RP, ET AL. Initial bronchoscopic treatment for patients with intraluminal bronchial carcinoids. J Thorac Cardiovasc Surg. 2007; 133: 973-8. http://dx.doi.org/10.1016/j. itcvs.2006.12.013

[18] NOWAK K, KARENOVICS W, NICHOLSON AG, JORDAN S, DUSMET M. Pure bronchoplastic resections of the bronchus without pulmonary resection for endobronchialcarcinoid tumours. Interact Cardiovasc Thorac Surg. 2013; 17: 291-4. http://dx.doi.org/10.1093/icvts/ivt154 